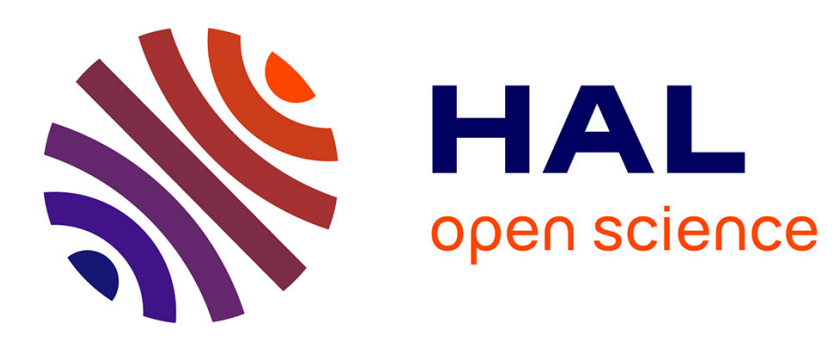

\title{
The Living Species is Not a Natural Kind but an Intellectual Construction \\ Philippe Grandcolas
}

\section{To cite this version:}

Philippe Grandcolas. The Living Species is Not a Natural Kind but an Intellectual Construction. Life Sciences, Information Sciences. Edited by Thierry Gaudin, Dominique Lacroix, Marie-Christine Maurel and Jean-Charles Pomerol. ISTE Ltd 2018. Published by ISTE Ltd and John Wiley \& Sons, Inc., ISTE and John Wiley \& Sons, Inc., pp.125-137, 2018. hal-02290754

\section{HAL Id: hal-02290754 https://hal.science/hal-02290754}

Submitted on 17 Sep 2019

HAL is a multi-disciplinary open access archive for the deposit and dissemination of scientific research documents, whether they are published or not. The documents may come from teaching and research institutions in France or abroad, or from public or private research centers.
L'archive ouverte pluridisciplinaire HAL, est destinée au dépôt et à la diffusion de documents scientifiques de niveau recherche, publiés ou non, émanant des établissements d'enseignement et de recherche français ou étrangers, des laboratoires publics ou privés. 


\title{
Chapitre 13 \\ The Living Species is Not a Natural Kind but an Intellectual Construction
}

\author{
Philippe GRANDCOLAS.
}

In: Life Sciences, Information Sciences, First Edition.

Edited by Thierry Gaudin, Dominique Lacroix, Marie-Christine Maurel and Jean-Charles

Pomerol.

ISTE Ltd 2018. Published by ISTE Ltd and John Wiley \& Sons, Inc. pp. 125-137

\subsection{Introduction}

In biology, the species is probably the most often and widely used notion. All scientific work on life refers to a species' name, as well as many other domains of civil society (nutrition, health, cosmetics, environmental management, gardening, etc.) However, the notion of species is also that on which opinions differ the most at the conceptual level. To give a measure of these divergences, we quote Mayden [MAY 97] who identified no less than 24 different concepts of species. Uncountable pages and numerous books have been written on the subject (recently, e.g., [STA 03, WHE 00]). Much work of philosophy of science puts an embarrassing emphasis on the contradictory and spirited discussions on the nature of a species [MAH 97, RUS 87, SOB 93]. The relatively confusing sum of all these works makes it difficult for scientists to fully embrace the question and adopt a reflective approach. This paradox - omnipresence of the notion and absence of a consensual concept - is a problem. In the largest majority, the uses of the notion of species are purely operational and do not mention any concept, which could limit the validity of the results or the data, or even the comparison of studies. Clearly, scientific communication concerning life can be problematic due to the issue about the notion of species.

This apparent cacophony is not the result of a lack of interest or perspicacity on the part of biologists but rather derives from the accumulation of concepts forged at different times by different disciplines whose objectives and tools vary or evolve.

Some people have attempted to combine these different concepts by adopting a sympathetic progressive attitude: the species is like a complex volume in the dark that can be lit up from different angles to ascertain its shape. Later, we will see that this attitude can create problems as it overestimates the reality of species and because the concepts refer to different situations whose compatibility varies greatly. Finally, the problem of the species is hidden behind a name, the one from the binomial Linnean nomenclature that gives it substance, authority and often prevents deeper awareness. A same name, especially if given cleverly in Latin with the authority of a descriptor taxonomist [DUB 08a], proclaims a sort of absolute equivalence that would erase the differences between concepts of species and would be far too easy to accept. This chapter reviews the main study methods used for evolution, the three main families of concepts of species that arise from these and finally the two great philosophical concepts on the nature of a species. To finish, we look at how to treat a species and the 
consequences of its use within the scientific community and its communication within society.

\subsection{Two ways to study evolution: genealogy versus phylogeny}

The main concepts of species are defined in the context of evolutionary biology. To understand these concepts, it is therefore necessary to first clarify the two main methods used to study the evolution, each addressing a different level and study method (Figures 13.1 and 13.2).

The level of genealogical study identifies and describes the relations between ancestors and descendants. The observations inevitably refer to individuals (Figure 13.1). They are either direct (the observation of reproduction and the birth of descendants) or indirect (inferences produced by population genetics methods). The diversity of genealogical relationships among living species is often underestimated due to our anthropocentrism: we consider a priori that life is only represented by pluricellular organisms with bisexual reproduction. In reality, bacteria, archaea and protists represent a substantial part of the living and even among the pluricellular, the modalities of reproduction can vary with parthenogenesis, the number of sexes (often greater than two), gender changes through development, etc. The genealogical level of study is the oldest and the most easily understood with anthropocentrism. Man has applied it to himself for millennia. Breeders construct the genealogy of many animal species and geneticists have formalized them since the beginning of the 20th Century [FIS 30]. 


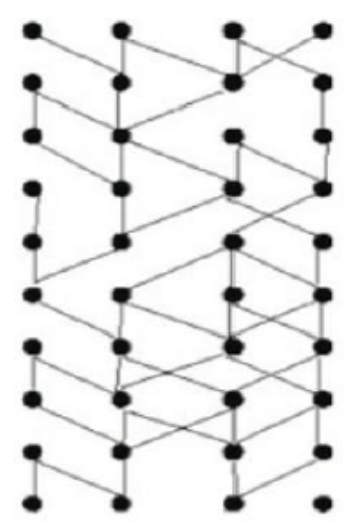

Figure 13.1. Genealogical level of study with network of reproduction relations in a group of ancestors and descendants; each black dot is an individual (adapted from [SAM 06])

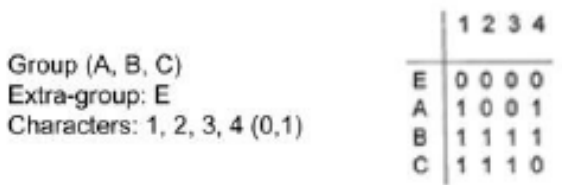<smiles>[Y]C(F)C([B])C</smiles>
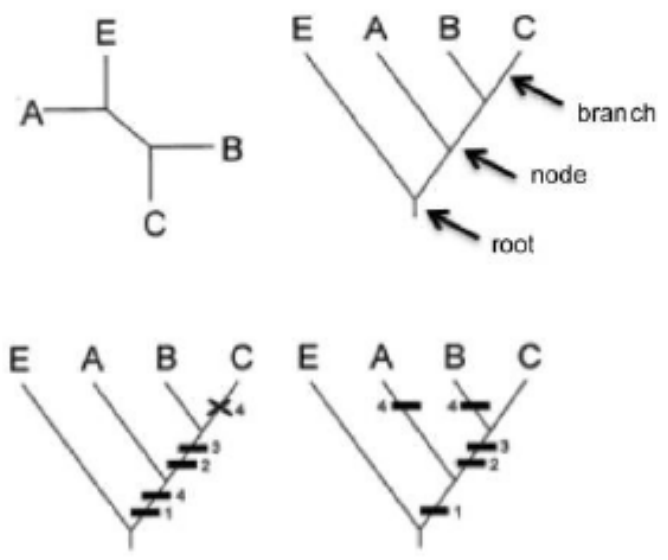

Figure 13.2. Phylogenetic tree of individuals (E, A, B, C) representing their relative and nested kinship relations. From top to bottom: samples, character matrices, non- rooted then rooted on the $\mathrm{E}$ individual tree and finally the two tree-solutions showing different changes in the state of characters. $B$ and $C$ are sister-groups, then $(B, C)$ is a sister-group of $A$. $(B, C)$ or $(A, B, C)$ form a group known as "monophyletic" 
Studies at the phylogenetic level describe evolutionary relationships (called sistergroups) between individuals or groups of individuals, at an observable level where genealogical information is often completely missing and unknowable. Evolutionary relations between individuals, known as phylogenies, are inferred through the shared presence of original characteristics (apomorphies) and are described in a relative manner: an individual is a closer relative to another individual than to a third one (Figure 13.2). These relative evolutionary relationships are hierarchically nested: they are represented by what are known as acyclic connected graphs - the phylogenetic trees or cladograms. Building these trees is therefore based on many original characteristics carried by the individuals and on the minimization of their changes of states. For example, horses are closer relatives to humans than fishes, which is attested by their shared possession of mammary glands and specific skeletal characteristics (jaw, inner ear, etc.), among others. Rejecting this inference is only possible if supported by many other characteristics that prove to be contradictory to those of mammary glands and the specific skeletal characteristics (between humans and fishes, for example). The process of minimization (the principle of parsimony) of changes in characteristics is now often carried out in a frequentist or Bayesian probabilistic context, notably for molecular data. A phylogenetic tree is therefore simply a graph, a representation of the results from calculations carried out on a matrix [individuals $\times$ characteristics]. Many misleading conceptions and language shortcuts try to give more significance to this graph than it is due, considering it as a natural kind, or as an image representation of evolution; thus, some people refer to ancestors at tree nodes or to the speciation of dichotomies. Nothing could be less true: potentially, ancestral states of characteristics at nodes can be reconstructed and it may be possible to study speciation using a phylogenetic tree, but these are particular uses that rely on the tree topology rather than on parts of or on the substance of the tree. The metaphor of genealogy most often used to explain phylogeny is particularly fallacious: in phylogeny, there are neither ancestors nor descendants; an ancestor at a given level is unknowable in phylogeny because it does not carry a single original characteristic [ENG 77, NEL 70]. Study at the phylogenetic level is very recent in its modern methodological dimension; phylogenetic analysis was formalized by Hennig [HEN 66], Kluge and Farris [KLU 69] and Farris [FAR 70]. This level of study still requires many methodological clarifications with an aim of eradicating all genealogical, essentialist or gradistic connotation [GRA 14].

\subsection{Three main families of concepts of species}

Rather than enumerating them exhaustively, it is possible to consider that the many different concepts [MAY 97] can be reassembled into three main groups [DUB 11, MAL 08a].

The first group - diagnostic concepts - is heterogeneous. It includes the first essentialist concepts from Aristotle to those that followed (Linné, Buffon, etc.) as well as all the operational groups made with existing individuals in the absence of more detailed concepts. It involves considering that two groups of individuals constitute just as many species if it is possible to find diagnostic characteristics for each of them. This group of concepts is limited by its simplicity: the delimitation of groups is arbitrary; it 
incorporates no or little theory of evolution and therefore does not allow for the testing of hypotheses in evolution biology.

The second group - biological concepts - is often attributed to the biologist Ernst Mayr [MAY 42]. It is based on the rupture from the principle of common reproduction and the adaptive or neutral genetic divergence and the reproductive isolation that should result from it. Two populations having undergone this type of event are deemed to de facto become two different species. Most geneticists or population biologists subscribe to this group of concepts that make the most sense in terms of the scale of their studies.

However, this group of concepts remains very limited by two problems, one theoretical and the other operational. Theoretically, the ability to reproduce together is an ancestral characteristic [BRE 79, ROS 78] and two very distant species are frequently able to reproduce, often with success. Think of ligers, walphins, camas and other zonkeys, not to mention one-quarter of the European flowering plant species or one-tenth of bird species hybrids [MAL 08a]. The ultimate paradox disfavoring this concept is that hybridization between what are considered as different species is often an engine of speciation, notably in plants. The criteria for reproduction that would define a species is therefore too idealistic to be pertinent. At the operational level, we must remember that this criterion only concerns a few organisms among all of the living: those that are plurisexual, especially those whose reproduction or genetic structure is observable, therefore only existing organisms excluding fossils (that represent $99.9 \%$ of the species that have existed!). For example, let us remember that the first discovery of fossil traces of copulation in vertebrates is very recent [JOY 12].

The third group - phylogenetic concepts - is the most recent [BAU 92, CRA 83]. It consists of anchoring diagnostic concepts in a phylogenetic context: the diagnostic characteristics of each species become the apomorphic characteristics supporting monophyletic phylogenetic groups (including all descendants from a common ancestor). These concepts are coherent with the historical and evolutionary context; they are applicable to all individuals without restriction (existing vs. fossil, for example). They also have the advantage of being predictors of genetic or phenotypic diversity, with the possible use of the phylogenetic diversity (PD) metric [FAI 92, PEL 16]. They can also be viewed as a modern formalization of Simpson's concept of evolving species [SIM 61] that has remained defective since its formulation, due to a lack of phylogenetic methodologies. A single concern remains: where do we put the limit between species?

\subsection{Reconciling the different concepts: pragmatism or essentialism?}

What is the theoretical compatibility between these groups of concepts? It is easy to see that it is not complete. Phylogenetic species have often proven to show traces of genetic introgression, implying that they do not correspond to closed communities of reproduction.

For example, Nattier et al. [NAT 12] led a study on the origins of restricted distribution (micro-endemism) in groups of insects in New Caledonia. For more than 20 million years, this group diversified through allopatric speciation; the distribution area of ancient species - much reduced in the beginning - increased in size, creating secondary sympatries that gave rise to interspecies reproduction whose traces are found in certain molecular markers. Conversely, it is commonly found that biological species are not monophyletic [FUN 03]. 
To compensate for this lack of complete compatibility and the clear disadvantage of recognizing pluralism in the notion of species, several scientists have conceived another kind of reconciliation between concepts: a composite concept called the lineage-species concept [DE 98, SAM 06]. These authors think that in time, a specific lineage successively encompasses first the phylogenetic species, then the biological species, once reproductive isolation is secondarily acquired. The incompatibilities raised at a time $t$ (see above) are only noted because they are observed at different moments in a situation that involves several steps.

This elegant proposition actually involves a very particular model of evolution in which reproductive isolation is acquired last, that is, far from universal. In some cases, reproductive isolation can be acquired first or secondarily lost in cases of extrinsic (geographic) isolation, also intervening secondarily. In addition, the phylogenetic species does not necessarily evolve fully into a biological species. The proposal of a composite lineage-species concept that can be considered as holistic or consensual therefore also has the disadvantage of leading to the thought that a species "truly exists" or will "truly" exist in an ulterior stage of evolution (once reproductive isolation is acquired): it falls back to a somewhat essentialist way of thinking. If the lineage-species concept is adopted, in fact only the observed stage of a given situation is adopted. In its entirety, the concept remains virtual and only holds sense through the syncretism of the different situations studied. It also hides the difficulty of considering all observations or inferences carried out at various study levels, populational and phylogenetic, and that ultimately do not refer to the same realities.

\subsection{The species and the taxon name}

No matter the species concept referred to (or not!), the species-taxon name is inevitably used. This is a Latin binome followed by the name of its author (e.g. Taraxacum officinale Weber, Blattella germanica L.) and whose qualities and rules of use are defined by the respective nomenclature codes of zoologists, botanists and microbiologists [DUB 08b]. The species-taxon name finds itself in the inclusive hierarchy of taxonomic categories: species, genus, family, sub-family, order, class, etc., that form a classification. The nomenclature rules associate this species-taxon name to a specific individual, the name-bearing type or holotype, more correctly called onomatophore. There is therefore a logical correspondence between species- taxon $<->$ name $<->$ holotype. Far from a typological view of organisms, this principle aims to prevent all later errors linked to the erroneous grouping of individuals: a single organism-individual bears the name. During the subsequent identification process, this taxon name is, by extension, attributed to one or more individuals based on diagnostic characteristics put forward during description. The Latin binomial name is therefore just a convenient label but through the years it has given substance to the species in the mind's spirit and sometimes substituted the definition of a species concept. Notably, the identification process that can be applied to all concerned organism-individuals leads to the idea that the species notion is linked to a finite group of individuals, that its boundaries can therefore be perfectly known and that, therefore, a concept is involved. Certain bionominalist conceptions feed on such confusion, thinking that creating names and a classification necessitates only that the entities designated by taxa have well- defined biological natures (see, e.g., [MAH 97]). It must be understood that taxonomic work on the "description of a species" is simply a process that consists of selecting a name-bearing type and defining a list of diagnostic 
characteristics that either subordinate it or distinguish it from preexisting taxa. As such, taxonomy is non-ambiguous, permitting the classification and subsequent identification of taxa. In reality, classification and taxonomy are simple language conventions that do not necessitate specific conceptual choices in terms of the species. In the extreme, it is even possible to imagine a completely utilitarian classification in which that taxa are innumerable drawers in a cabinet library and do not have any particular significance. Let us therefore imagine a library organized in chronological order of work acquisition rather than by subject.

Of course, a "natural" classification with an evolutionary and biological logic would be much more informative and useful, just as access to a library organized by subjects or authors would be much easier and more informative. Nevertheless, as much as it is preferable to follow an evolutionary classification, it also draws general utilitarian strength by not being directly and automatically dependent on versatile evolutionary theories (e.g. contradictory phylogenetic trees) that would continually modify it.

\subsection{The nature of species: a salutatory philosophical exercise}

Philosophers and biologists who pride themselves on philosophy have long discussed the nature of living species. This debate on nature is not only a point of philosophical theory, as many biologists are often happy to think. It also sheds light on the discussion on species concepts and vice versa. Three main concepts on the nature of species have emerged: the species as a natural kind, the species as an individual and the species as a class [RUS 87].

The species as a natural kind has renewed itself since Aristotle and Locke and their essentialist concepts. Today, it is defended as such in a materialist ontology (e.g. [MAH 97]) through the conjunction of several properties or laws that are linked in a constant and real manner. However, species do not show such characteristics, they are polymorphous, variable and, most notably, they evolve and do not constantly have these characteristics. The natural kind concept, whose most frequently quoted example refers to the elements of the periodic table, is not in accordance with biological reality, even if perceived through the prism of one or another species concept. To support this theory, Boyd [BOY 91] and then Griffith [GRI 99] rearranged the concept of the natural kind into "homeostatic property cluster kinds", an "elastic class" whose variability is compensated for by the continuity of homeostatic properties that guarantee its integrity. Such rearrangement kills the concept of the natural kind and renders it trivial. The species as an individual was recently claimed [GHI 74, HUL 78] as a solution to the inadequacy of the natural kind. An individual is restricted in space and time: it has a beginning and an end. An interesting consequence is that an organism-individual can then become part of the species-individual instead of being a member of a kind.

Organisms are therefore more causally linked (matched?) than similar. Here again, there is a difficulty in adopting this nature of a species. In fact, organisms of a species lack cohesion: they are not part of a unified whole but are simply linked by potential reproduction relationships. In addition, the genealogical link is not, strictly speaking, causal. Identifying the beginning and end of a species falls back on limiting it precisely in space and time with all its organism-individuals, which is biologically incompatible with the different concepts. It is understood that this is more an analogy than a characterization. 
We see that these different natures are forced to adjust to species concepts with which they do not fit. Their point in common is their attempt to reify species and give them a tangible biological reality, beyond the biological concepts describing the loose and close relations between individuals or the historical phylogenetic diagnoses that simply give a final score of the relations between groups of organism- individuals.

Why not ultimately characterize species as a less tangible group, an extensional class (see class definition according to [MAH 97]) thus characterized by the statement of one or more properties common to a set of individuals. These properties would simply be diagnostic characteristics to which the status of law or invariant would not be attached: for example the ability to reproduce together, the list of apomorphic characteristics. This characterization that could be qualified as nominalist (in its strict sense) would, in addition, be compatible with the pluralist view of species, recognizing the validity and particularity of each family of concepts, whether biological or phylogenetic. It is therefore possible to formulate different, partially compatible classes corresponding to each family of concepts.

Biologically, this solution leads to the postulate that the only reality is the organismindividual (the one that is observable from one's window, not the one whose structure is inferred) and its relationships with other organism-individuals, as many times and in as diverse ways as they can be characterized in. Historically, it is interesting to note that this solution is closer to Darwin's concepts, remarkably significant and economical in hypothesis [MAL 08a, MAL 08b, STA 13].

Consider species as a simple extensional class that has the following consequences: - the name of the species carried by the name-bearing type (onomatophore) is attributed through the process of identification to a class of organism-individuals; ideally, such an attribution would require detailing the species concept used and would remain dependent on this concept: with the identification operation, the field of classification - the species-taxon free from biological theory - is combined with that of evolutionary biology - a defined concept of species;

- all judicial notions linked to a species name designate the name-bearing type and its identified conspecifics;

- it is necessary to revisit all the analyses in evolutionary biology and to realize that they are only truly relevant in terms of organism-individuals (contra [WHE 00]); phylogenetic studies study the evolutionary relationships between individuals, even if they use characteristics that are quite invariable among the individuals attributed to different species-classes. The concept of speciation must be well-understood: it does not correspond to species individualization but to a change in relationships between individuals, etc.

- the character postulated and conditional on the identification operation also requires that information linked to the living species be used and conserved at the organismindividual level; this is the notion of "saving information" that underpins the conservation of the organism-individual similar to so many specimens in collections [GRA 17]; - empirically, due to the fact that a large majority of species are defined operationally and in a purely taxonomic and diagnostic manner, they can be considered to issue from the phylogenetic species concept, provided that the classification is natural (that is to say that the diagnoses are established from characteristics that are known, from phylogenetic analyses, to be apomorphic at the level concerned). 
There remains one thing to say with regard to the delimitation of species. We have seen that in terms of the different concepts, none of them guarantees an unequivocal delimitation. The shared criterion of reproduction is far from absolute and the criterion of monophyly does not prescribe where to cut off two species. In both cases, the method is the same: discontinuities that appear significant are used to make species statements (e.g. [MAL 08a]): defining classes is an easier task when based on relatively constant differences and particularities. Since Darwin [DAR 59], it has been understood in addition that these apparent discontinuities between groups of individuals called species are the combined result of divergences and extinctions [MAL 08a, MAL 08b]. For example, delimitation methods have been proposed based on hiatus in the overall similarity between molecular markers [PUI 12]. It goes without saying that this type of delimitation carries a strong arbitrariness but remains legitimate in the context of the definition of a simple class (neither a natural kind, nor an individual). The authors generally argued for the biological legitimacy of the characteristics used for species delimitation: such and such anatomical characteristic is supposedly less adapted (less suspected of convergence?), more adapted (more stable?), a genetic characteristic (e.g. a DNA barcode) rather than phenotypic (stronger heritability, more prone to statistical analysis?), etc. There are, of course, many assumptions in such arguments and it must simply be remembered that it is more coherent to justify characteristics used with regard to the species concept followed rather than in terms of pure operationality. This would lead to the selection of apomorphic characteristics in the case of the phylogenetic concept or linked to reproduction in the case of the biological species.

In this manner, the definition of a species is the result of a specific study that consequently proposes a simple extensional class. The species is therefore not discovered as a tangible entity, it is not subject to evolution [MAL 08a, MAL 08b]: to be clear, we cannot speak of the evolution of a species and that which evolves, these are the relationships between organism-individuals. The title of Darwin's famous book - The Origin of Species - must be understood as a metaphor and not as a demonstration per se.

\subsection{Bibliography}

[BAU 92] BAUM D., "Phylogenetic species concepts”, Trends in Ecology \& Evolution, vol. 7, no. 1, pp. 1-2, 1992.

[BOY 91] BOYD R., "Realism, anti-foundationalism and the enthusiasm for natural kinds", Philosophical Studies, vol. 61, no. 1, pp. 127-148, 1991.

[BRE 79] BREMER K., WANNTORP H.E., "Geographic populations or biological species in phylogeny reconstruction”, Systematic Zoology, vol. 28, pp. 220-224, 1979.

[CRA 83] CRACRAFT J., "Species concepts and speciation analysis", Current Ornithology, vol. 1, pp. 159-187, 1983.

[DAR 59] DARWIN C., On the Origin of Species by Means of Natural Selection, or the Preservation of Favoured Races in the Struggle for Life, John Murray, London, 1859. [DE 98] DE QUEIROZ K., "The general lineage concept of species , species criteria, and the process of speciation: a conceptual unification and terminological recommendations", in HOWARD D.J., BERLOCHER S.H. (eds), Endless Forms: Species and Speciation, Oxford University Press, New York, 1998. 
[DUB 08a] DUBOIS A., "A partial but radical solution to the problem of nomenclatural taxonomic inflation and synonymy load", Biological Journal of the Linnean Society, vol. 93, pp. 857-863, 2008.

[DUB 08b] DUBOIS A., "Le Code international de nomenclature zoologique :

présentation, philosophie, règles majeures, problèmes actuels", in PRAT D., RAYNALROQUES A., ROGUENANT A. (eds), Peut-on classer le vivant? Linné et la systématique aujourd'hui, Éditions Belin, Paris, 2008.

[DUB 11] DUBOIS A., "Species and 'strange species' in zoology: do we need a 'unified concept of species'?”, Comptes Rendus Palevol, vol. 10, no. 2, pp. 77-94, 2011.

[ENG 77] ENGELMANN G.F., WILEY E.O., "The place of ancestor-descendant relationships in phylogeny reconstruction”, Systematic Zoology, vol. 26, pp. 1-11, 1977. [FAI 92] FAITH D.P., "Conservation evaluation and phylogenetic diversity”, Biological Conservation, vol. 61, pp. 1-10, 1992.

[FAR 70] FARRIS J.S., "Methods for computing Wagner trees", Systematic Zoology, vol. 19, pp. 83-92, 1970.

[FIS 30] FISHER R.A., The Genetical Theory of Natural Selection, Oxford University Press, Oxford, 1930.

[FUN 03] FUNK D.J., OMLAND K.E., "Species-level paraphyly and polyphyly: frequency, causes, and consequences, with insights from animal mitochondrial DNA", Annual Review of Ecology and Systematics, vol. 34, pp. 397-423, 2003.

[GHI 74] GHISELIN M.T., "A radical solution to the species problem”, Systematic Biology, vol. 23, no. 4, pp. 536-544, 1974.

[GRA 14] GRANDCOLAS P., NATTIER R., TREWICK S., "Relict species: a relict concept?", Trends in Ecology \& Evolution, vol. 29, no. 12, pp. 655-663, 2014.

[GRA 17] GRANDCOLAS P., "Loosing the connection between the observation and the specimen: a by-product of the digital era or a trend inherited from general biology?", Bionomina, vol. 12, pp. 57-62, 2017.

[GRI 99] GRIFFITHS P., "Squaring the circle: natural kinds with historical essences", in WILSON R. (ed.), Species: New Interdisciplinary Studies, MIT Press, Cambridge, 1999. [HEN 66] HENNIG W., Phylogenetic Systematics, University of Illinois Press, Urbana, 1966.

[HUL 78] HULL D.L., "A matter of individuality”, Philosophy of Science, vol. 45, pp. 335$360,1978$.

[JOY 12] JOYCE W.G., MICKLICH N., SCHAAL S.F.K. et al., "Caught in the act: the first record of copulating fossil vertebrates", Biology Letters, vol. 8, no. 5, pp. 846-848, 2012. [KLU 69] KLUGE A.G., FARRIS J.S., "Quantitative phyletics and the evolution of anurans", Systematic Zoology, vol. 18, pp. 1-32, 1969.

[MAH 97] MAHNER M., BUNGE M., Foundations of Biophilosophy, Springer, Berlin, 1997. [MAL 08a] MALLET J., "Hybridization, ecological races and the nature of species: empirical evidence for the ease of speciation", Philosophical Transactions of the Royal Society of London B: Biological Sciences, vol. 363, no. 1506, pp. 2971-2986, 2008. [MAL 08b] MALLET J., "Mayr's view of Darwin: was Darwin wrong about speciation?”, Biological Journal of the Linnean Society, vol. 95, no. 1, pp. 3-16, 2008.

[MAY 42] MAYR E., Systematics and the Origin of Species, from the Viewpoint of a Zoologist, Harvard University Press, Cambridge, 1942.

[MAY 97] MAYDEN R.L., "A hierarchy of species concepts: the denouement in the saga of the species problem", in CLARIDGE M.F., DAWAH H.A., WILSON M.R. (eds), Species: The Units of Diversity, Chapman and Hall, London, 1997. 
[NAT 12] NATTIER R., GRANDCOLAS P., ELIAS M. et al., "Secondary sympatry caused by range expansion informs on the dynamics of microendemism in a biodiversity hotspot", PLoS ONE, vol. 7, e48047, 2012.

[NEL 70] NELSON G.J., "Outline of a theory of comparative biology", Systematic Zoology, vol. 19, pp. 373-384, 1970.

[PEL 16] PELLENS R., GRANDCOLAS P. (eds), Biodiversity Conservation and Phylogenetic Systematics: Species Protection in an Extinction Crisis, Springer Open, 2016.

[PUI 12] PUILLANDRE N., LAMBERT A., BROUILLET S. et al., "ABGD, automatic barcode gap discovery for primary species delimitation”, Molecular Ecology, vol. 21, pp. 18641877, 2012.

[ROS 78] ROSEN D.E., "Vicariant patterns and historical explanation in biogeography”, Systematic Zoology, vol. 27, pp. 159-188, 1978.

[RUS 87] RUSE M., "Biological species: natural kinds, individuals, or what?", British Journal for the Philosophy of Science, vol. 38, pp. 225-242, 1987.

[SAM 06] SAMADI S., BARBEROUSSE A., "The tree, the network, and the species", Biological Journal of the Linnean Society, vol. 89, no. 3, pp. 509-521, 2006.

[SIM 61] SIMPSON G.G., Principles of Animal Taxonomy, Columbia University Press, New York, 1961.

[SOB 93] SOBER E., Philosophy of Biology, Westview Press, Boulder, 1993.

[STA 03] STAMOS D.N., The Species Problem: Biological Species, Ontology, and the Metaphysics of Biology, Lexington Books, Lanham, 2003.

[STA 13] STAMOS D.N., "Darwin's species concept revisited”, in PAVLINOV I. (ed.), The Species Problem: Ongoing Issues, InTech, Rijeka, 2013.

[WHE 00] WHEELER Q.D., MEIER R. (eds), Species Concepts and Phylogenetic Theory, Columbia University Press, New York, 2000. 